\title{
Spontaneous caudicle reconfiguration in Dactylorhiza fuchsii: A new self-pollination mechanism for Orchideae
}

\author{
Izabela Tałałaj ${ }^{1}$ D . Jarosław Kotowicz ${ }^{2} \cdot$ Emilia Brzosko $^{1} \cdot$ Beata Ostrowiecka $^{1} \cdot$ Olgierd Aleksandrowicz $^{1}$. \\ Ada Wróblewska ${ }^{1}$
}

Received: 29 August 2018 / Accepted: 11 February 2019 / Published online: 20 February 2019

(c) The Author(s) 2019

\begin{abstract}
Deceptive plants represent a strategy that promotes outcrossing and protects against facilitated selfing. However, deception does not eliminate the possibility of autonomous self-pollination when pollinators are scarce or absent. Spontaneous autogamy is widespread in Orchidaceae, but the scale, mechanism, time of appearance and effectiveness remain underestimated. Using field and laboratory observations and experiments, for the first time, we documented the possibility of autonomous self-pollination in the deceptive orchid Dactylorhiza fuchsii, which might occur through the previously unspecified mechanism in the tribe Orchideae of caudicle reconfiguration. Self-pollination occurred through the pollinarium twisting to the side and downwards, which was different than caudicle bending forward on the body of pollinators. Caudicle reconfiguration was continuously distributed during anthesis and was common in the studied populations. This mechanism was independent on the flower position in the inflorescence, but was sensitive to pollinator activity. (The frequency of caudicle reconfiguration increased when more pollinaria in the inflorescence were untouched.) This process was effective (self-pollination leading to autogamous fruits and seeds) only when a full caudicle rotation occurred and the pollinium touched the stigma. However, most caudicle reconfigurations were completed before the stigma was reached, resulting in less than $1 \%$ of autogamous pollination in the studied populations.
\end{abstract}

Keywords Autogamy $\cdot$ Caudicle bending movement $\cdot$ Reproductive success $\cdot$ Self-pollination

\section{Introduction}

One of the major selective forces acting on the evolution of plant breeding systems and directly related with the adaptation of floral traits is avoidance of inbreeding (Barrett 2003; Charlesworth 2006; Brys and Jacquemyn 2016). In hermaphroditic, self-incompatible plants, there are many adaptations to reduce self-pollination (Lloyd and Schoen 1992), ranging from morphological adaptations, e.g. dichogamy or herkogamy (Barrett 2002), to some functional strategies, such as deception (Jersáková et al. 2006). However,

Handling Editor: Peter K. Endress.

Izabela Tałałaj

izagry@uwb.edu.pl

1 Institute of Biology, University of Bialystok, ul. Ciołkowskiego 1J, 15-245 Białystok, Poland

2 Institute of Mathematics, University of Bialystok, ul. Ciołkowskiego 1M, 15-245 Białystok, Poland pollinator availability is the primary factor limiting reproductive success in most angiosperms, and self-pollination may guarantee some reproductive assurance (Lloyd 1979, 1992). Selfing can be the exclusive breeding system or combined with cross-fertilization as part of mixed mating (Goodwillie et al. 2005; Goodwillie and Knight 2006; Johnston et al. 2009; Porcher et al. 2009).

The time and the mechanism of self-pollination remain the subject of debate in many plant taxa and offer opportunities to increase our knowledge of the evolution of mating systems and floral traits (Zhang and Li 2008; Freitas and Sazima 2009; Brys et al. 2013; Bateman et al. 2015; Suetsugu 2015; Love et al. 2016; Yang et al. 2018). One of the problematic subjects is the functional approach of facultative autogamy (occurrence during a flower's life span and contribution to breeding system), which has often been overlooked. The functional studies emphasizing the operation of facultative self-pollination mechanisms acting in autogamy demonstrate that this pollination mode usually occurs at the end of anthesis, after pollinators have failed 
and after opportunities for outcrossing (Tałałaj and Brzosko 2008; Freitas and Sazima 2009; Suetsugu 2013). Therefore, delayed selfing should be favoured when pollinators are sometimes unreliable. Conversely, when self-pollination occurs during anthesis, it competes with cross-pollination (Lloyd and Schoen 1992). However, when pollinators are deficient, competing selfing may offer a selective advantage because the investment of resources in traits associated with attracting pollinators and optimizing visits is reduced, for example, floral longevity and size or nectar production (Yang et al. 2018). In reality, autogamous selfing does not fall into strict classes of floral life span and is instead continuously distributed (Goodwillie et al. 2005). The appearance and extent of autonomous selfing may differ among closely related species (Brys and Jacquemyn 2011; Kalisz et al. 2012; Yang et al. 2018), different populations of a single species and even between years within the same population (Kalisz et al. 1999; Elle et al. 2010; Brys et al. 2013; de Gusmão Lôbo and Stefenon 2018).

Autonomous selfing is widespread in the Orchidaceae, and the phenomenon apparently evolved independently many times in this family (Catling 1990). Deficiency of pollinators is often documented in orchid populations (Tremblay et al. 2005), and autonomous self-pollination provides a reproductive assurance, when the frequency of pollination is unreliable. Despite obligatory autogamy, there are many studies that report cases of facultative autogamy occurring at the end of a flower's life span (reviewed in Catling 1990; Claessens and Kleynen 2011). Some cases of facultative autogamy are accidental or even questionable. However, some of the data also document a continuous distribution of self-pollination starting from the beginning of anthesis and occurring in combination with cross-pollination, such as in Pseudorchis albida (Claessens and Kleynen 2011).

Orchids display various mechanisms of self-pollination, including oversecretion of the stigma, different movements of the perianth, stigma, anther or pollinia, and numerous structural modifications (Catling 1990). One of the interesting mechanisms promoting autogamy is caudicle bending leading to a gradual reorientation of the pollinium. Most European orchids with caudicles as structural parts of the pollinaria exhibit caudicle bending on an insect body after withdrawal of the pollinarium from the flower (Claessens and Kleynen 2011), which is caused by the rapid dehydration of the part by which the caudicle is connected to the viscidium (Darwin 1877). On the one hand, caudicle bending brings the pollinia into appropriate position for touching the stigma; on the other hand, this movement occurs at different times after removal from the anther, depending on pollinator behaviour on the inflorescence. This mechanism is usually thought as prevention against selfing through geitonogamy and functions as an adaptation for outcrossing (Darwin 1877; Johnson and Edwards 2000; Peter and Johnson 2006).
Paradoxically, caudicle bending may have been exploited to facilitate the evolution of selfing through spontaneous autogamy, but little is still known about the mechanism, timing and contribution of caudicle bending to autonomous selfing. Catling (1990) listed approximately 16 orchid species among the entire family with auto-pollination through bending of the caudicle, stalklet or pollen mass. Claessens and Kleynen (2011) reported 17 European orchid species auto-pollinate through bending of the caudicle. Among these species, 5 species were identified as obligatorily autogamous and 2 species as facultatively autogamous, and for 10 species, this mechanism was recognized as accidental or questionable. This list continues to be augmented (Suetsugu 2013, 2015; Tałałaj and Skierczyński 2015). Accidents of caudicle bending within flowers (without data about self-fertilization) were noted in three species widely distributed in Europe in the genus Dactylorhiza: D. maculata, D. incarnata and D. majalis (Martens 1926; Groll 1965; Reinhard 1977; Dressler 1981). Claessens and Kleynen (2011) questioned the presence of this autogamous process in Dactylorhiza and stated that this genus is only allogamous.

In the present study, we examined the self-compatible $D$. fuchsii (Waite et al. 1991; Tałałaj et al. personal observation), which has been reported as strictly pollinator-dependent (Vakhrameeva et al. 2008; Claessens and Kleynen 2011). Research on the pollination biology of this orchid conducted in Polish forests (Białowieża and Augustów) demonstrated caudicle bending on a pollinator body during pollinarium transport (Gutowski 1990). This movement requires approximately $22.7 \mathrm{~s}$ after withdrawal of the pollinarium from the flower (Claessens and Kleynen 2011). However, spontaneous caudicle bending within $D$. fuchsii flowers and spontaneous autogamy through this mechanism have not been reported (Claessens and Kleynen 2011). Studying the breeding system of orchids in Poland, we recorded flowers of $D$. fuchsii with pollinaria self-withdrawn from the thecae and reconfigured. In the present study, we asked the following: (1) What is the process of caudicle reconfiguration, does it frequently occur within natural populations, and if so, at what stage of floral development? (2) Is caudicle reconfiguration a mechanism that effectively leads to self-pollination in $D$. fuchsii?

\section{Materials and methods}

\section{Study species}

Dactylorhiza fuchsii (Druce) Soó is a terrestrial orchid belonging to the Orchideae tribe (subfamily Orchidoideae) that is widely distributed in Europe and Siberia. It occurs in a wide range of habitats, including open forests (both broadleaved and coniferous forest), bush groves and meadows 
(Vakhrameeva et al. 2008). In Poland, the species is mainly found on clay sandy and loamy soils (Kamińska et al. 1990). The flowering shoots of $D$. fuchsii form elongate $(6-10 \mathrm{~cm}$ long) and dense spikes (10-30 (65) flowers) (Vakhrameeva et al. 2008). Flowers are lilac-pink and the labellum with purple loops, spots and dashes (Box et al. 2008). The base of the labellum surrounds the entrance to the nectarless spur (Dafni 1987). However, reports suggest the presence of some rewards (Dafni and Woodell 1986; Box et al. 2008). D. fuchsii is self-compatible (Waite et al. 1991) but is reported as a pollinator-dependent plant. Claessens and Kleynen (2011) collected available reports of approximately 24 pollinator species of Coleoptera, 3 species of Diptera and 9 species of Hymenoptera. Percentage fruit set of this species varied among populations from different parts of the geographical range between 10.6 and $53.7 \%$ (Vakhrameeva et al. 2008; Claessens and Kleynen 2011).

The gynostemium of $D$. fuchsii is short, erect, and the gynoecium is firmly fused with the anther. The anther is erect and tapering towards the base and contains two parallel chambers covered by anther thecae, which are thin walled, narrowed and partially free at the base, opening with a slit. Each theca contains one pollinarium with a club-shaped, sectile pollinium (composed of massulae) and a filiform, elastic caudicle, which is attached to a separate, sticky viscidium. Both viscidia are enclosed in the same bursicle. The anther is raised above the rostellum and receptive surface of the stigma. The rostellum is three-lobed, perpendicular to the receptive surface and forming a roof-like projection above the stigma. This structure is thought to prevent against self-pollination. The stigma of $D$. fuchsii is also three-lobed, but the major part of the receptive surface is formed of lateral carpels, which are broad and clearly visible within the neck of the spur entrance (Szlachetko and Rutkowski 2000; Box et al. 2008; Claessens and Kleynen 2011).

\section{Study sites}

Studies were conducted in northeastern Poland in three populations located in natural habitats of the Biebrza Valley (the

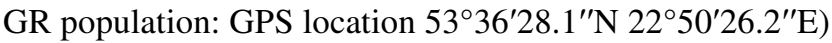
and the Białowieża Forest (populations BR: GPS location $52^{\circ} 50^{\prime} 59^{\prime \prime} \mathrm{N} 23^{\circ} 53^{\prime} 40^{\prime \prime} \mathrm{E}$ and CM: GPS location $52^{\circ} 41^{\prime} 03^{\prime \prime} \mathrm{N}$ $23^{\circ} 39^{\prime} 07^{\prime \prime}$ E). Population GR was located in the Grzędy Reserve at the transition zone of oak-linden-hornbeam forest (Tilio-Carpinetum) and alder carr forest (Ribeso-nigri Alnetum). The BR population was situated in the Białowieża Natural Forest Reserve at the transition zone of Tilio-Carpinetum and riverside carr forest (Circaeo-Alnetum). The CM population was located in the Nieznanowo Reserve, along the clearings of an inactive forest railway running through Tilio-Carpinetum community. In the populations studied, the number of flowering shoots was approximately 250 in GR,
200 in BR and 150 in CM. At these sites, D. fuchsii flowers in June and July and sets fruit in mid-August. Flowers are pollinated by Coleoptera, Diptera and Hymenoptera (Tałałaj et al. in prep.).

\section{The process of caudicle reconfiguration (cr)}

To document caudicle reconfiguration, flowers at various phases of anthesis, derived from randomly chosen shoots, were monitored in situ in the GR population during 2014. Details of caudicle reconfiguration and movement of the whole pollinarium were visualized using photography. To compare the trajectory of caudicle movement within flowers with caudicle movement on the insect body, randomly chosen pollinaria were pulled out from the thecae by a wooden toothpick and time-lapse recorded with a camera. To check the elasticity of the caudicles, a few pollinaria that were pulled out were also artificially charged with a water drop, and a few were set in motion with a light gust of breath.

\section{Caudicle reconfiguration at the population level}

Because caudicle reconfiguration was recorded in fresh and withered flowers, we assumed that the full qualitative and quantitative results on caudicle reconfiguration would be obtained at the end of the flowering phase. When all the flowers on the inflorescence were post-anthesis, each flower on the inflorescence was inspected (using a $10 \times$ magnifying glass) to document the position of the pollinarium (analysed for both thecae) and with respect to flower position on the inflorescence (bottom, middle and top). We distinguished the following stages of the pollinaria (pollinaria were included in the analysis when position of the viscidium was unchanged): P0, both thecae empty, pollinaria removed by pollinators; P1, one or two pollinaria present, enclosed in the thecae; P2, both pollinia outside the thecae rotated on the caudicles; P3, one theca with enclosed pollinium and one pollinium outside the theca rotated on the caudicle; $\mathbf{P 4}$, both pollinia outside the thecae rotated on the caudicles and one pollinium touching the stigma; $\mathbf{P 5}$, one theca with enclosed pollinium and one pollinium outside the theca rotated on the caudicle and touching the stigma; $\mathbf{P 6}$, both pollinia outside the thecae rotated on the caudicles and both touching the stigma; P7, one theca empty, pollinarium removed by a pollinator and one pollinium outside the theca rotated on the caudicle; P8, one theca empty, pollinarium removed by a pollinator, and one pollinium outside the theca rotated on the caudicle and touching the stigma. We also recorded whether pollinia outside the theca (stages P2, P3, P4, P7) crumbled into massulae. At fruit maturation, we focused on the flowers with spontaneous caudicle reconfiguration and recorded whether they set fruits. We noted also the position of these fruits in the inflorescence. 
Field observations were conducted in the GR population during 2014 and 2015 on 102 and 52 randomly chosen inflorescences and 1691 and 1082 flowers, respectively. Observations were completed in the BR population in 2014 on 19 inflorescences and 370 flowers.

\section{Time of caudicle reconfiguration}

To document the frequency of caudicle reconfiguration during anthesis, this process was monitored at two blooming phases on 31 randomly chosen inflorescences in the GR population in 2015. In phase1, most flowers in the inflorescence were freshly opened (3rd July), and in phase 2, all flowers were withered (17th July). In phase1, we observed only flowers with fresh sepals (416 flowers), which were reanalysed in phase 2 . In both phases, we recorded the stages of the pollinarium (P0-P8).

\section{Quantity and quality of seeds}

In 2014 in the GR population, we collected 72 fruits from 14 inflorescences, which were produced from flowers at different positions in the inflorescence and represented different pollinarium stages at the end of anthesis. Seeds from the particular capsules were equally distributed in Petri dishes with a $6 \times 6$ grid of squares $(1 \times 1 \mathrm{~cm})$. The number of squares in a sample necessary for analysis was set at 11 (at the confidence level of 0.02). Using the pseudorandom number generator implemented in the $\mathrm{R}$ environment ( $\mathrm{R}$ Core Team 2017), a series of random eleven-element trials were selected for use in further research. A stereomicroscope (OLYMPUS SZX2-ILLT, objective DFPL 0.5X-4, with the software cellSens Standard) was used for capturing and analysing each of the 11 photographed squares with seeds using MultiScan v.14.02 software. Median and contrast filters were added to enhance the contrast for seed counting. Based on the number of seeds counted in 11 squares, we estimated the total sum of seeds per capsule. We also counted properly formed seeds (with clearly visible and swollen embryos) versus those improperly formed (with embryos abnormally shaped or differing in colour) to evaluate the fraction of properly developed seeds per capsule. Lengths of three properly formed and randomly chosen seeds per each capsule were also measured. During analysis, we discretized fractions of properly developed seeds using the octiles.

\section{Pollination experiment}

To assess the efficiency of spontaneous caudicle reconfiguration within flowers as the mechanism promoting autogamy, inflorescences of $D$. fuchsii were covered with a nylon mesh bag from the bud stage until the end of anthesis to exclude the pollinators. This experiment was performed in each population, over 2 years, and included the following number of inflorescences/flowers: GR2014: 7/155, GR2015: 3/55, BR2014: 9/262, BR2015: 9/255, CM2015: 9/192, CM2016: 4/90. At fruit maturation, we checked the number of fruits. In the BR population in 2014, after the experiment of spontaneous autogamy, flowers on 9 inflorescences (262 flowers) were analysed in terms of stages P1-P6 of the pollinarium. In other populations and years, analysis was impossible because of damage to the gynostemium.

\section{Results}

\section{Mechanism of caudicle reconfiguration}

Caudicle reconfiguration was observed in flowers with both fresh and withered sepals. Regardless of whether the theca was opened or closed, caudicle reconfiguration began with caudicle folding at $1 / 3$ of the height from its base (Fig. 1c, d). Afterwards, the caudicle became convex in half its length and pulled the pollinium out of the theca. The pollinium was twisted to the side and downwards. Finally, the pollinium adhered to the stigma receptive surface (Fig. 1a, b). Caudicle reconfiguration was completed at various moments in this movement, which was taken into consideration in methods and results.

The caudicles that were pulled out of the thecae manually were projected almost perpendicularly on a wooden toothpick at first and then they bent forward (Fig. 1e-h). The bending movement was localized at the point at which the caudicle joined the viscidium. Pollinaria that were artificially charged with a water drop bent at $1 / 3$ of the height from its base (Fig. 1i, j). A light gust of breath caused the pollinia and the longer stretch of the caudicles to shake and swing, whereas the basal part of the caudicles remained rigid (Fig. 1k-m).

\section{Caudicle reconfiguration at the population level}

At the end of anthesis, caudicle reconfiguration ( $\mathrm{cr}$ ) within flowers (P2-P8) was recorded in 0.66/GR2014, 0.80/ GR2015 and 0.60/BR2014 of the inflorescences. When found on an inflorescence, $c r$ was noted in up to 8 flowers but was most often in 1-3 flowers per inflorescence (Fig. 2). The average fraction of flowers with $\mathrm{cr}$ per inflorescence in the populations was from 0.07/BR2014 to 0.12/GR2014, and the highest fraction of the flowers with $\mathrm{cr}$ per single inflorescence was from 0.22/BR2014 to even 1.0/GR2014 (Table 1). The fraction of the pollinaria with $\mathrm{cr}$ in the inflorescence was dependent on the fraction of available pollinaria in the inflorescence (Pearson's Chi squared statistic: GR2014 $\chi^{2}=16.06, d f=9, P=0.05$; GR2015 $\chi^{2}=31.96$, $d f=9, P<0.001 ;$ BR2014 $\left.\chi^{2}=20,27, d f=6, P<0.01\right)$. 

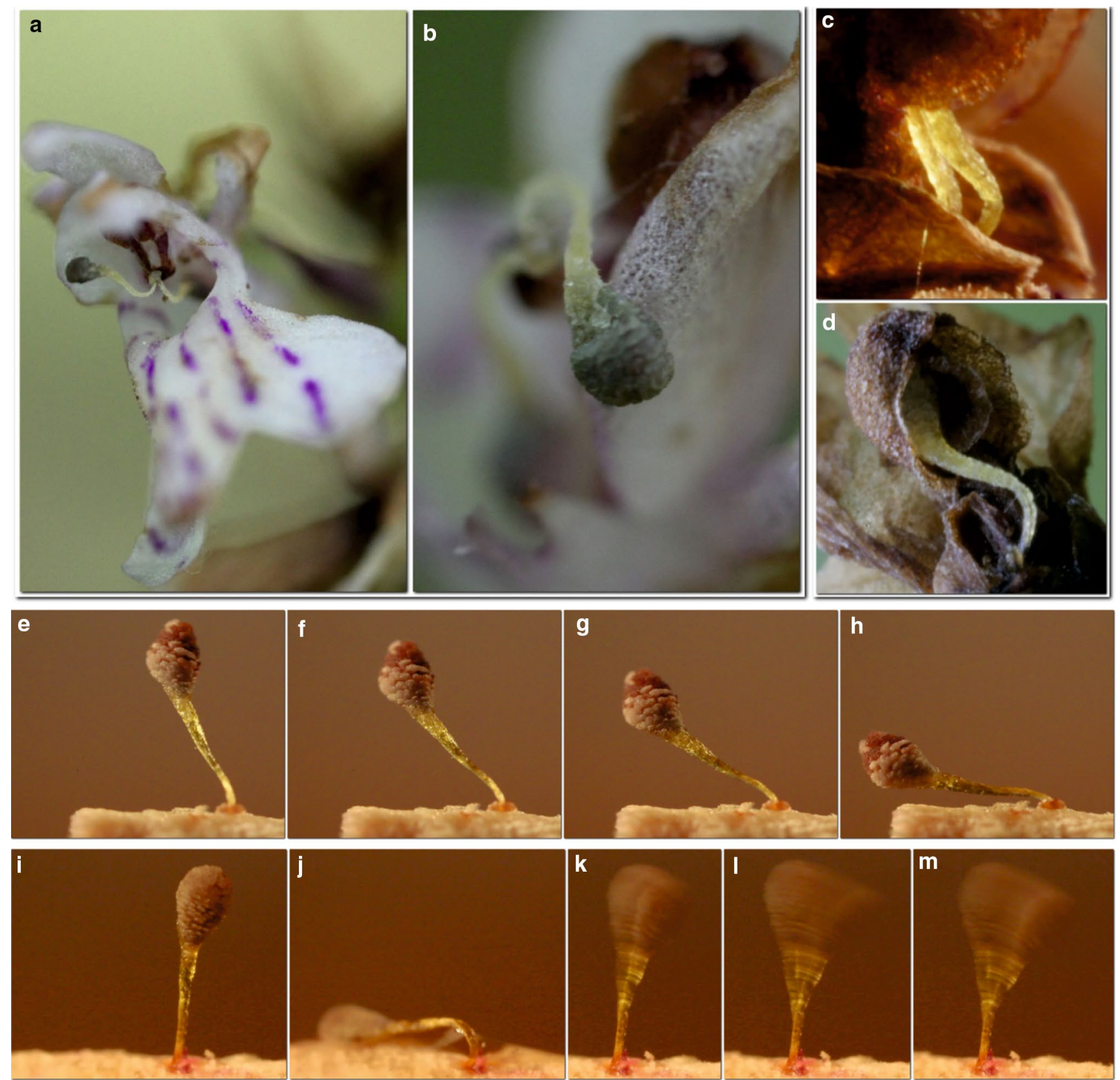

Fig. 1 Caudicle rotation within flowers of Dactylorhiza fuchsii. a, b One pollinarium twists to the side, and the second touches the stigma. c, $\mathbf{d}$ The beginning phase of caudicle bending within a flower. $\mathbf{e}-\mathbf{h}$
The mechanism of caudicle bending movement on an insect body. $\mathbf{i}, \mathbf{j}$ The pollinarium artificially charged with a water drop. $\mathbf{k}-\mathbf{m}$ The pollinarium artificially set in motion with a light gust of breath
Hence, the fraction of the flowers in stages P2-P8 was highest in the position on the inflorescence in which the fraction of the flowers in the P0 stage was lowest (Fig. 3). Flowers with $c r$ were significantly the most frequent at the upper position in GR2014 and GR2015 (Pearson's Chi-squared statistic: $\chi^{2}=92.63$ and $\chi^{2}=57.04, d f=4, P<0.001$ ), whereas in BR2014, those with $c r$ were noted more often at the bottom but this effect was not significant $\left(\chi^{2}=5.32, d f=4\right.$, $P=0.256)$. In both populations, flowers with only one or two pollinia outside the theca (stages P2, P3, P7) were recorded more often (with the fraction from 0.17 to 0.43 ) than flowers with at least one pollinium touching the stigma (stages P4, P5, P6, P8, with the fraction from 0.0 to 0.1) (Fig. 4). We found that pollinia outside the theca crumbled into massulae only in the GR population, with the fraction of 0.04 of the flowers with $c r$ during 2014 and 0.06 during 2015 . Within the particular stages of the pollinarium, the fraction was from 0.25 to 0.27 of the flowers with the P2 stage, from 


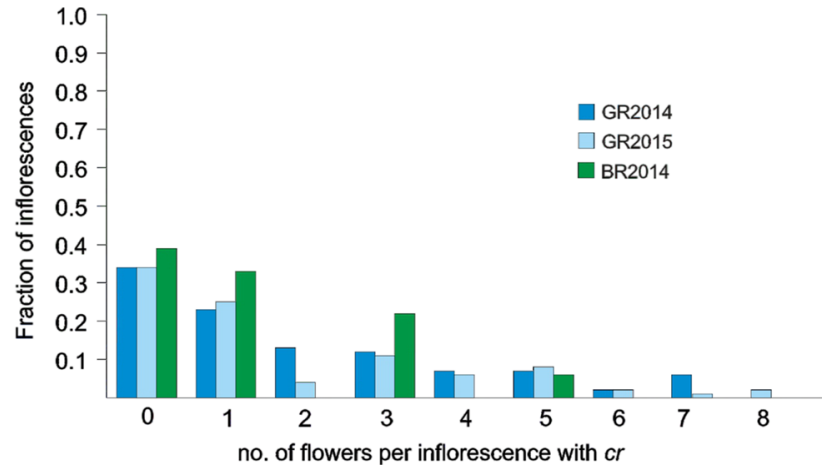

Fig. 2 Fraction of open-pollinated inflorescences representing different number of flowers with caudicle reconfiguration $\mathrm{cr}$ recorded at the end of anthesis in two populations of Dactylorhiza fuchsii during 2 years

0.08 to 0.25 of the flowers with the P3 stage, from 0.0 to 0.33 of the flowers with the P4 stage and from 0.10 to 0.32 of the flowers with the P7 stage (Fig. 3).

Fruits developed from 0.28 /GR2014 to $0.33 /$ GR2015 of P2-P8 flowers. In both populations, this level of fruiting was lower than fruit set for P0 flowers, whereas compared with the fruit set on P1 flowers; this level of fruiting was at a similar level in the GR population and was twofold higher in the BR population (Fig. 5). In both populations in each year of the study, the fraction of fruits developed from the flowers with $c r$ was not dependent on the flower position on the inflorescence (Pearson's Chi-squared statistic, $P>0.05$ ). However, reproductive success was significantly differentiated among the flowers with different P2-P8 pollinarium stages (Pearson's Chi-squared statistic: GR2014 $\chi^{2}=27.15$, $d f=6, P<0.001 ;$ GR2015 $\chi^{2}=18.42, d f=5, P<0.01$; BR2014 $\left.\chi^{2}=8.38, d f=3, P<0.05\right)$. Fruits developed more frequently from the flowers with at least one pollinium touching the stigma (Fig. 6). In the GR population in both years, within the fruits developing from the flowers with pollinia outside the thecae (stages P2, P3, P4 and P7), the fractions of 0.07 and 0.08 were recorded from flowers with massulae crumbling.

\section{Time of caudicle reconfiguration}

In total, we controlled 223 flowers with one or two pollinaria present in the thecae during phase1. Among the controlled

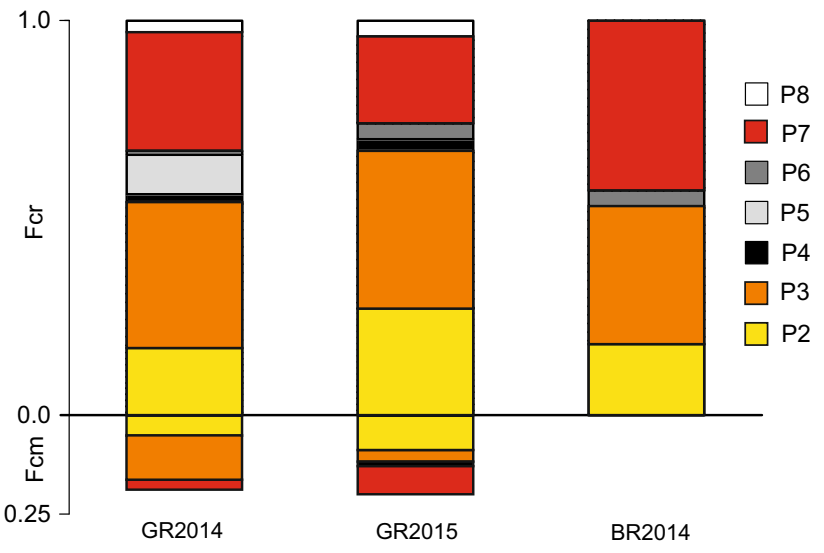

Fig. 3 Fraction of the pollinarium stages with caudicle reconfiguration F $r$ and fraction of the particular stage of the pollinarium crumbling into massulae Fcm recorded at the end of anthesis in open-pollinated flowers in two populations of Dactylorhiza fuchsii (GR and BR) during 2 years (2014 and 2015). Abbreviations P2-P8 are explained in "Materials and methods" section. The greyscale boxes represent flowers with at least one pollinium spontaneously touching the stigma. The coloured boxes represent flowers with only one or two pollinia outside the theca

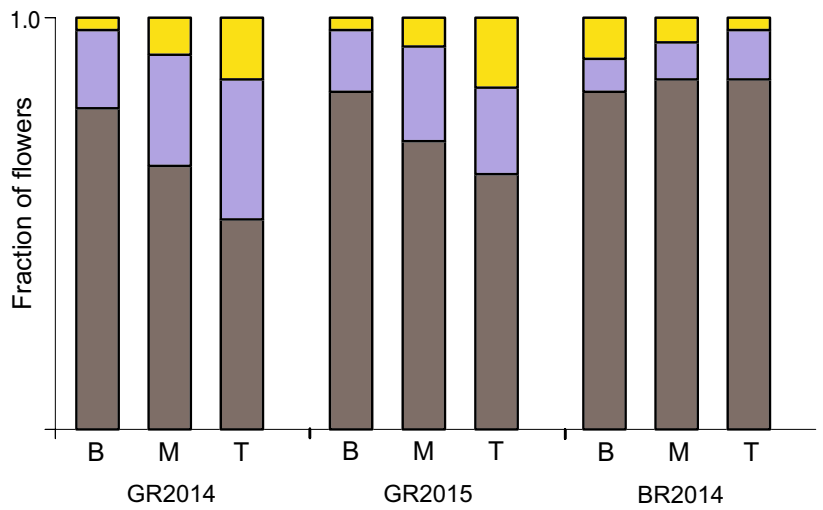

Fig. 4 Fraction of the flowers without pollinaria ( $\mathrm{P} 0$; the brown boxes), without caudicle reconfiguration ( $\mathrm{P} 1$; the violet boxes) and with some caudicle reconfiguration (P2-P8; the yellow boxes) at three positions on the inflorescence, $\mathrm{B}$-bottom, $\mathrm{M}$-middle, $\mathrm{T}$ - top, recorded in two populations of Dactylorhiza fuchsii (GR and BR) during 2 years (2014 and 2015) at the end of anthesis. Abbreviations P0-P8 are explained in "Materials and methods" section

flowers, 119 did not show any $c r$ (stage P1) and within 104 flowers some $\mathrm{cr}$ was observed. From the flowers with
Table 1 Fraction of the flowers $F_{\mathrm{FL}}$, with caudicle reconfiguration recorded in two populations of Dactylorhiza fuchsii during 2 years of the study

\begin{tabular}{lllllll}
\hline Population (year) & Average $F_{\mathrm{FL}}$ & \multicolumn{6}{l}{ Tukey five-number summaries for $F_{\mathrm{FL}}$} & \\
\cline { 3 - 7 } & & Min. & $Q 1$ & $Q 2$ & $Q 3$ & Max. \\
\hline GRZ2014 & 0.12 & 0.00 & 0.00 & 0.07 & 0.14 & 1.00 \\
GRZ2015 & 0.09 & 0.00 & 0.00 & 0.05 & 0.15 & 0.50 \\
BRO2014 & 0.07 & 0.00 & 0.00 & 0.05 & 0.14 & 0.22 \\
\hline
\end{tabular}




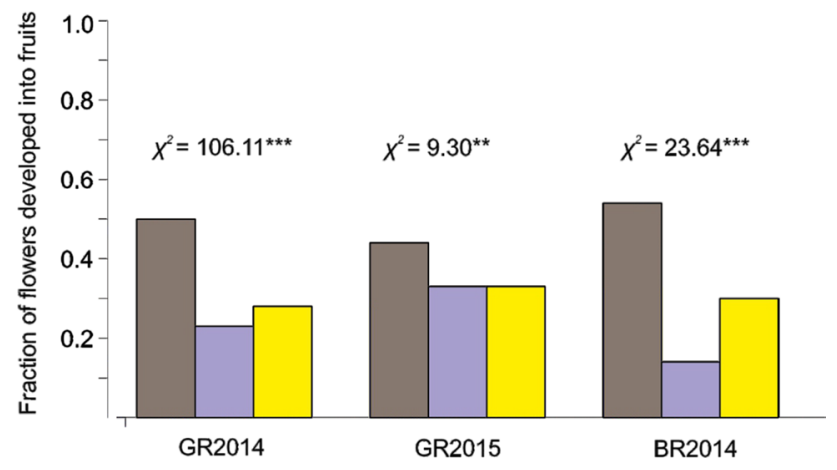

Fig. 5 Fraction of fruits recorded from the flowers with pollinaria exported (P0; the brown boxes), without caudicle reconfiguration ( $\mathrm{P} 1$; the violet boxes) and with some caudicle reconfiguration ( $\mathrm{P} 2-$ P8; the yellow boxes) recorded in two populations of Dactylorhiza fuchsii (GR and BR) during 2 years (2014 and 2015) at the end of anthesis. Abbreviations $\mathrm{P} 0-\mathrm{P} 8$ are explained in "Materials and methods" section. Pearson's Chi-squared statistic: $P<0.05^{*}, P<0.01^{* *}$, $P<0.001 * * *$

some $c r$ in phase 1 during fruit maturation, we recorded 29 fruits. Among these fruits, 0.72 were previously recorded as a swollen ovary during the first control in phase1 (stages: $\mathrm{P} 2=4$ fruits, $\mathrm{P} 3=6$ fruits, $\mathrm{P} 4=3$ fruits, $\mathrm{P} 5=1$ fruit, $\mathrm{P} 7=5$ fruits, $\mathrm{P} 8=2$ fruits), 0.12 were recorded from the flowers with both pollinaria removed by pollinators in phase 2 and 0.36 were noted from the flowers that changed to other than the initial stage of P2-P8. (Single fruits were recorded from the flowers that changed as follows: P3 $\rightarrow$ P4, P3 $\rightarrow$ P6, P3 $\rightarrow$ P7, P4 $\rightarrow$ P8.).

\section{Quantity and quality of seeds}

The capsule position on the inflorescence (bottom, middle and top) significantly influenced the number of seeds per capsule (ANOVA: $F_{2,72}=11.84, P<0.001$ ) and the length of seeds (ANOVA: $F_{2,72}=3.17, P<0.05$ ). Seed production per capsule decreased from the bottom $(\bar{x}=2988.3 \pm 789.8)$ to the top $(\bar{x}=1771.8 \pm 910.6)$ of the inflorescence, whereas the length of seeds increased from the bottom $(\bar{x}=0.821$ $\pm 0.08 \mathrm{~mm})$ to the top $(\bar{x}=0.843 \pm 0.06 \mathrm{~mm})$ of the inflorescence. In orchids, seed quality and quantity are usually correlated with fruit position in the inflorescence (Tremblay et al. 2005). Therefore, both parameters were further analysed on top-located capsules, the most numerous and diverse in terms of pollinarium stages. Only the fraction of properly developed seeds was not dependent on the capsule position in the inflorescence (ANOVA: $F_{2,72}=2.06$, $P=0.14)$.

Both parameters, seed number and seed length, were not significantly different among the particular pollinarium stages compared separately or grouped in various combinations of the stages of pollinarium and the number of pollinaria removed by pollinators (Pearson's Chi-squared statistic, $P>0.05)$. Only the fraction of properly developed seeds was dependent on the pollinarium stage (Pearson $\chi^{2}=71.63$, $d f=49, P=0.022$ ). On the scatter plot, the fractions of properly developed seeds (positioning with the octiles) are distributed at each of the intervals for the pollinarium stages P0 and P3, are grouped at the middle intervals for the pollinarium stages $\mathrm{P} 1$ and $\mathrm{P} 2$ and are divided into two groups of low and high fractions of proper seeds for pollinarium stages P4-P8 (Fig. 7).

\section{Pollination experiment}

After the bagging experiment, we recorded 3 fruits set spontaneously on 2 shoots in the BR2014 population. The fruits were at the bottom, middle and top positions on the infructescence. Single fruits were also recorded in the
Fig. 6 Fraction of fruits developed from the flowers with different pollinarium stages at the end of anthesis recorded in two populations of Dactylorhiza fuchsii (GR and BR) during 2 years (2014 and 2015). Abbreviations P2-P8 are explained in "Materials and methods" section. The greyscale boxes represent flowers with at least one pollinium spontaneously touching the stigma. The coloured boxes represent flowers with one or two pollinia only hanging free outside the theca

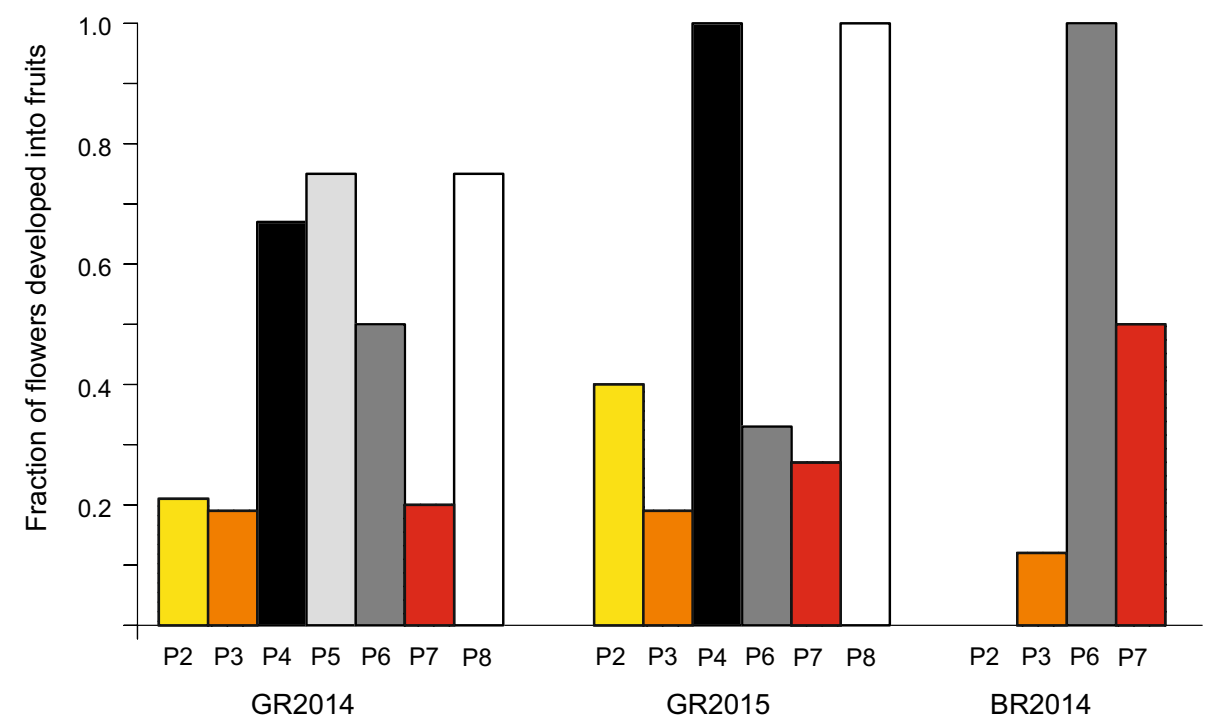


Fig. 7 Distribution of the fraction of properly developed seeds (partitioned with the octiles) recorded in the GR population during 2014 on the flowers representing different pollinarium stages at the end of anthesis. Abbreviations P0-P8 are explained in "Materials and methods" section

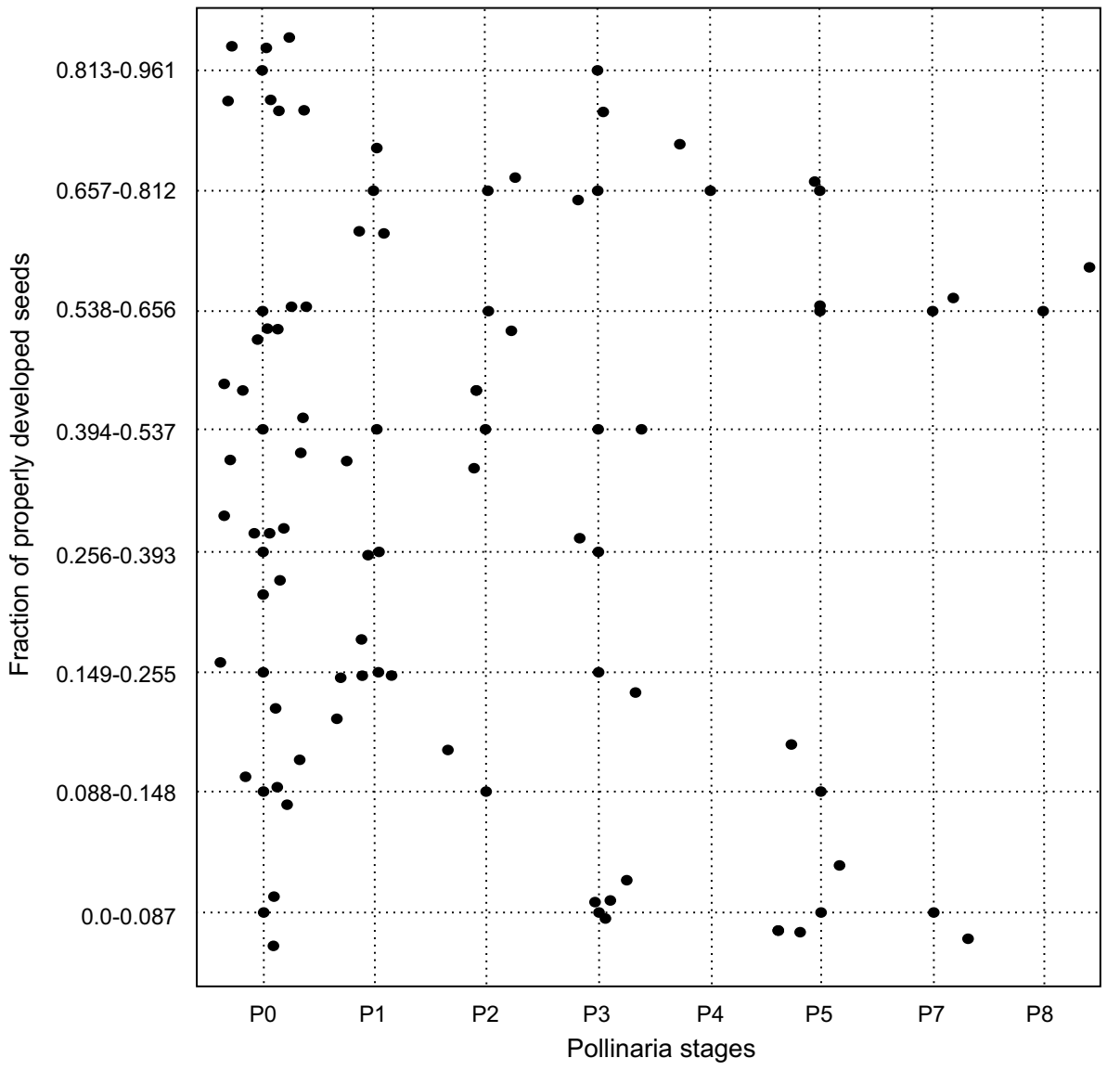

populations CM2015 and CM2016 at the bottom and middle positions, respectively, of the infructescence. Unfortunately, we could not define pollinarium stages preceding the fruit development in the population CM. At the end of anthesis, in the BR2014 population, caudicle reconfiguration within flowers was recorded on 8 of 9 the inflorescences covered with a cotton mesh. The frequency of flowers with $\mathrm{cr}$ per inflorescence varied from 0.07 to 0.72 , and when present, $c r$ was independent of the flower position in the inflorescence (Pearson $\chi^{2}=13.52, d f=12, P=0.332$ ). The position in the inflorescence also did not determine the stages of the pollinarium (Pearson $\chi^{2}=13.52, d f=12, P=0.332$ ) or fruit formation (Pearson $\chi^{2}=0.001, d f=2, P=0.999$ ). Among the flowers with $c r$, the pollinaria observed most often were from the stages $\mathrm{P} 2$ at $0.20, \mathrm{P} 3$ at 0.35 and $\mathrm{P} 4$ at 0.42 , and the most rare ones were from the stages P5 at 0.02 and P6 at 0.01 . However, only flowers with stages P5 and P6 of the pollinaria formed fruits spontaneously.

\section{Discussion}

Our study documents a new pollination mechanism, which has not been described for the genus Dactylorhiza and other members of the tribe Orchideae. In most cases, self-pollination in Orchideae occurs when pollinia fragments or the entire pollinium falls onto the stigmatic surface, and because of bending of the caudicles. Autogamy through caudicle bending movement is well known in Ophrys apifera (Darwin 1877), P. albida, Neotinea maculata, Gennaria diphylla and Serapias parviflora (Moggridge 1865; Claessens and Kleynen 2011). In these species, when thecae open widely, pollinaria fall out of anthers because of caudicle bending, gravity or external factors. In S. parviflora, the caudicle bends forward somewhat and disintegrated massulae fall onto the stigma (Moggridge 1865). In G. diphylla, the extremely short caudicles have a ribbon-like shape, which allows the pollinia to fall sideways and to contact with the stigma receptive lobe (Claessens and Kleynen 2011). In $O$. apifera, after within flower caudicle rotation forward, pollinaria hang free in the air in front of the stigma. A weak point that enables the caudicle to swing freely in all directions contains hollow spaces inside the caudicle (Darwin 1877; Claessens and Kleynen 2002). In flowers of Dactylorhiza majalis, Darwin (1877) described bending of the pollinaria, whereas Martens (1926) found that the pollinaria continue to stand upright, and the entire pollinium falls onto the stigmatic surface. Accidental autogamy through caudicle bending movement is also recorded for $D$. incarnata (Martens 1926). In D. maculata, the pollinaria dislodge and lean 
forward without touching the stigma (Martens 1926). In $D$. viridis, whether pollinarium fragments can fall spontaneously onto the stigmatic surface is questionable (Hagerup 1952).

We recorded that in $D$. fuchsii, pollinaria did not fall out from the theca and did not bend forward, but the pollinium leaned out from the theca by the caudicle (independent of whether the theca was open or closed). We supposed that the pressure of the pollinium on a long and flexible caudicle caused it at first, to bend and become convex between the elastic and rigid parts of the caudicle. Subsequently, the pollinium was twisted to the side and downwards (until touching the stigma) mechanically, under gravity and most likely under dehydration at the point at which a caudicle was connected to the viscidium, which is the rule for a caudicle bending movement on an insect body (Darwin 1877). Whereas the elastic part of a caudicle ensures the breakage between pollinium and viscidium during pollinaria import and export (Johnson and Edwards 2000), the rigid, basal part of a caudicle of $D$. fuchsii apparently stabilized both, with gradual bending on an insect body and also a caudicle reconfiguration within a flower.

In $D$. fuchsii, $c r$ is apparently a common process that is independent of flower position in the inflorescence. The fraction and position of the flowers with $\mathrm{cr}$ in the inflorescence provided confirmation of this statement as recorded during anthesis (GR2015), at the end of anthesis (populations GR and BR) and under a cotton net (BR2014). Most of these movements finished at different positions outside the theca without touching the stigma. The mechanical caudicle rotation within flowers of $D$. fuchsii, similar to that of O. apifera, is opposed to the proactive floral movements against gravity observed in, e.g. Holcoglossum amesianum (Liu et al. 2006). However, in O. apifera, wind is an important final factor, which makes the pollinia swing and touch the stigma because plants placed indoors did not drop any pollinia from the thecae, whereas in the field, over $67 \%$ of the pollinia outside the theca adhered to the stigma (Kullenberg 1961; Claessens and Kleynen 2002). In Liparis loeselii, self-pollination through bending of the stipe or rotation increases significantly by the action of rain striking the flowers (Catling 1980). Our studies on open flowering plants and plants blooming under the net demonstrated that the pollinia adhered to the stigma without external factors. The fraction of all pollinarium stages with at least one pollinium touching the stigma was even higher in the pollination experiment (BR2014 population, 0.45) than that with open flowers during anthesis (GR2015 population, 0.08) and after anthesis (populations GR2014, 0.16, GR2015, 0.11, BR2014, 0.04). Knowledge remains scarce about the anatomy of orchid anthers and the once-off reconfiguration movements of caudicle (Peter and Johnson 2006). Therefore, the question of what factor limits the full rotation of the caudicles in $D$. fuchsii remains open. The answer to this question is crucial because we recorded that pollinium adhering to the stigma led to autogamy in $D$. fuchsii. Single fruits that were set under the cotton nets developed from self-pollination after one or two pollinia adhered to the stigma. In the open flowering plants, fruiting success was also highest in the flowers with at least one pollinium touching the stigma at the end of anthesis. However, because pollinarium stages with at least one pollinium touching the stigma were rare in the flowers during anthesis, at the end of anthesis and under the cotton nets, fruits were set very rarely. The entire pollinium causing self-pollination of terrestrial orchids is a much more rare case than that of only pollinium fragments, which are sufficient for self-pollination [reviewed in Catling (1990) and Claessens and Kleynen (2011), Bateman et al. (2015)]. In our studies, crumbling of the pollinia outside the theca at the end of anthesis was recorded very rarely only in the GR population, during both years. For the particular pollinarium stages with the pollinia hanging free outside the thecae, massula disintegration was differentiated between the years, although the similar maximum fraction of approximately 0.30 records was achieved for each pollinarium stage $\mathrm{P} 2$, P3, P4 and P7. Whereas spatial and temporal differences in pollinium disintegration within the same flower may result from differences in the habitat humidity (Catling 1990; Peter and Johnson 2006; Tałałaj and Skierczyński 2015), we found that the habitat played a minor role in auto-pollination and fruit development of $D$. fuchsii.

We found that caudicle reconfiguration within flowers of D. fuchsii began at the beginning of anthesis and was completed at the end. Previous studies documented autogamy in the genus Dactylorhiza in the late stage of flower development (Darwin 1877; Martens 1926; Groll 1965; Dressler 1981; Catling 1983). Our results confirm that the timing of spontaneous self-pollination in plants may be continuously distributed (Goodwillie et al. 2005; Brys et al. 2013; Yang et al. 2018). In the rewarding orchid P. albida, Claessens and Kleynen (2011) recorded different combinations of both cross- and self-pollination through autogamy starting from the beginning of anthesis. They demonstrated that autogamy is incorporated into the normal pollination pattern of this species, does not fall into strict time-classes and is not a last resort strategy. In the studied populations of $D$. fuchsii, the extension in time of the variation in cross-pollination and caudicle reconfiguration leading to self-pollination was dependent on the activity of the pollinators. When flowers of D. fuchsii were not exposed to pollinators (under the cotton nets), caudicles reconfigured more often and independently of the flower position in the inflorescence. However, when flowers were exposed to pollinators (open flowering plants at the end of anthesis), caudicles reconfigured more often at those positions in the inflorescence at which pollinators were less active (more pollinaria were available). These 
results indicate that when pollinator visits decrease, populations may shift towards intermediate selfing rates through an increase in the proportion of caudicle reconfiguration. Therefore, caudicle reconfiguration represents a pollination mechanism sensitive to unpredictable pollinator environments, which is the norm in wild plant populations, particularly in deceptive species (Tremblay et al. 2005; Jersáková et al. 2006).

Because of the temporal variation in both availability of the pollinaria and their position (stage) within flowers, and because of the foraging behaviour of the pollinators within an inflorescence (Hymenoptera, Coleoptera and Diptera), which promote both cross-pollination and self-pollination through geitonogamy or facilitated autogamy (Tałałaj et al. unpublished data), the fruit and seed origins in D. fuchsii can be manifold. In theory, each flower that we observed at the end of anthesis (P0-P8) could be cross-pollinated or self-pollinated through geitonogamy. Facilitated autogamy was possible for the stages P0, P1 (when one pollinarium was removed), P7 and P8. Spontaneous autogamy was possible for the stages P4, P5, P6 and P8 and before one or two pollinaria were removed for the stages P0, P1 and P7. We assumed two reference pollinarium stages: P0 and P1. In each studied population and year, more fruits were set from the flowers with the highest effectiveness of the pollinators (stage P0 with both pollinaria removed), and the recorded fruiting level of ca. 50\% did not exceed the maximum value given for other populations of $D$. fuchsii (reviewed in Claessens and Kleynen 2011). Additionally, in the GR2014 population, fractions of properly developed seeds that formed from P0 flowers were continuously distributed from the lowest to highest intervals of the range, suggesting that the breeding system, amounts of self versus cross-pollen deposited on the stigma, and the number of individuals from which the pollen was derived could have occurred in a variety of combinations in P0 flowers (Goodwillie et al. 2005). In contrast to P0, in each studied population and year, fruiting was significantly reduced in flowers with the lowest effectiveness of pollinator activity and with the lowest potential of caudicle reconfiguration (stage P1 with one or two pollinaria inside the thecae). In the GR2014 population, fractions of properly developed seeds recorded in fruits developed from P1 flowers were concentrated in the middle part of their distribution, without extreme values. Compared with both reference stages (P0 and P1), the fruiting level from the flowers with some caudicle reconfiguration (P2-P8) was at the same level as that for $\mathrm{P} 1$ in the GR population and the median of $\mathrm{P} 1$ and $\mathrm{P} 0$ in the BR population. However, considering fruiting from the flowers representing a particular pollinarium stage with caudicle reconfiguration, this result was due to the high share of the flowers with both pollinaria present in which pollinia did not touch the stigma (stages P2 and
P3) and represented a fruiting level similar to that of P1. Furthermore, the distribution of correctly developed seeds that were formed in fruits from the P2 and P3 flowers demonstrated a similar breeding system to that of the reference stages $\mathrm{P} 1$ and $\mathrm{P} 0$. In the BR2014 population, a high share of the flowers had one pollinarium removed by pollinators and one pollinarium reconfigured (stage $\mathrm{P} 7$ ), half of which became fruits. When, in each population and year, flowers with at least one pollinium touching the stigma (stages P4, P5, P6, P8 and potentially P7 in time) were represented by the highest fraction, fruiting was on a significantly higher level than that of P1. However, the fraction of correctly developed seeds would be expected to be very low or high, without intermediate values, which does not relate to any reference stage (P0 or P1). A notable result was that the origin of seeds was different for $\mathrm{P} 0-\mathrm{P} 3$ than that for seeds developed in fruits from the P4-P8 flowers. The revealed disjunction of properly developed seeds might result from post-zygotic selection (Goodwillie et al. 2005; Johnston et al. 2009; Porcher et al. 2009), and further studies on a larger fruit sample are required.

\section{Conclusions}

Dactylorhiza fuchsii is a deceptive orchid species with a generalist pollination syndrome that suffers from an unpredictable pollinator environment. On the one hand, the strategy of food deception protects against facilitated selfpollination and promotes cross-pollination (Jersáková et al. 2006), but, on the other hand, the strategy does not eliminate the possibility of autonomous self-pollination when pollinators are scarce or absent (Catling 1990; Claessens and Kleynen 2011). For the first time, we documented the possibility of autonomous self-pollination in $D$. fuchsii and the tribe Orchideae, which might occur through the previously unspecified mechanism of caudicle reconfiguration. This raises the question whether this is a local phenomenon, or whether it is a much more widespread, but completely overlooked mechanism that may contribute to autonomous selfing in many more orchid species? This mechanism was effective only when a full caudicle rotation occurred and the pollinium touched the stigma. When pollinaria were present in the flowers until the end of anthesis, caudicle rotation was common and continuously distributed throughout the floral life span, but self-pollination was rare. Importantly, the scale and effectiveness of caudicle reconfiguration in other parts of the species geographical range must be determined to identify the factor responsible for the full caudicle rotation mechanism, which may be an important selective factor in the evolution of autogamy in $D$. fuchsii. 
Acknowledgements The authors would like to thank Paweł Mirski and Karolina Pieńczykowska for help in field observation. We also thank the anonymous reviewers for the comments to improve the manuscript.

Funding This research was funded by a grant from the National Science Center in Poland (No. 2013/09/B/NZ8/03350).

\section{Compliance with ethical standards}

Conflict of interest The authors declare that they have no conflict of interest.

OpenAccess This article is distributed under the terms of the Creative Commons Attribution 4.0 International License (http://creativeco mmons.org/licenses/by/4.0/), which permits unrestricted use, distribution, and reproduction in any medium, provided you give appropriate credit to the original author(s) and the source, provide a link to the Creative Commons license, and indicate if changes were made.

\section{References}

Barrett SCH (2002) The evolution of plant sexual diversity. Nat Rev Genet 3:274-284. https://doi.org/10.1038/nrg776

Barrett SCH (2003) Mating strategies in flowering plants: the outcrossing-selfing paradigm and beyond. Phil Trans Roy Soc London B Biol Sci 358:991-1004. https://doi.org/10.1098/rstb.2003.1301

Bateman RM, Sramko G, Rudall PJ (2015) Floral miniaturisation and autogamy in boreal-arctic plants are epitomised by Iceland's most frequent orchid, Platanthera hyperborea. PeerJ 3:e894. https://doi. org/10.7717/peerj.894

Box MS, Bateman RM, Glover BJ, Rudall PJ (2008) Floral ontogenetic evidence of repeated speciation via paedomorphosis in subtribe Orchidinae (Orchidaceae). Bot J Linn Soc 157:429-454. https:// doi.org/10.1111/j.1095-8339.2008.00794.x

Brys R, Jacquemyn H (2011) Variation in the functioning of autonomous self-pollination, pollinator services and floral traits in three Centaurium species. Ann Bot (Oxford) 107:917-925. https://doi. org/10.1093/aob/mcr032

Brys R, Jacquemyn H (2016) Severe outbreeding and inbreeding depression maintain mating system differentiation in Epipactis (Orchidaceae). J Evol Biol 29:352-359. https://doi.org/10.1111/ jeb. 12787

Brys R, Geens B, Beeckman T, Jacquemyn H (2013) Differences in dichogamy and herkogamy contribute to higher selfing in contrasting environments in the annual Blackstonia perfoliata (Gentianaceae). Ann Bot (Oxford) 111:651-661. https://doi.org/10.1093/ $\mathrm{aob} / \mathrm{mct} 031$

Catling PM (1980) Rain-assisted autogamy in Liparis loeselii (L.) L. C. Rich. (Orchidaceae). Bull Torrey Bot Club 107:525-529. https ://doi.org/10.2307/2484083

Catling PM (1983) Autogamy in eastern Canadian Orchidaceae: a review of current knowledge and some new observations. Nat Canada 110:37-53. https://doi.org/10.2307/2805948

Catling PM (1990) Auto-pollination in the Orchidaceae. In: Arditti J (ed) Orchid biology. Reviews and perspectives, vol. V. Timber Press, Portland, pp 121-158

Charlesworth D (2006) Evolution of plant breeding systems. Curr Biol 16:726-735. https://doi.org/10.1016/j.cub.2006.07.068

Claessens J, Kleynen J (2002) Investigations on the autogamy in Ophrys apifera Hudson. Jahresber Naturwiss Vereins Wuppertal 55:62-77
Claessens J, Kleynen J (2011) The flower of the European orchid. Form and function. Schrijen-Lippertz, Voerendaal

Dafni A (1987) Pollination in Orchis and related genera: evolution from reward to deception. In: Arditti J (ed) Orchid biology. Reviews and perspectives, vol. 4. Cornell University Press, Ithaca, pp 79-104

Dafni A, Woodell SRJ (1986) Stigmatic exudate and the pollination of Dactylorhiza fuchsii (DRUCE) Soó. Flora (Jena) 178:343-350. https://doi.org/10.1016/s0367-2530(17)31521-9

Darwin CR (1877) The various contrivances by which orchids are fertilized by insects, 2nd edn. John Murray, London. https://doi. org/10.5962/bhl.title. 57232

de Gusmão Lôbo CC, Stefenon VM (2018) Floral morphometric analysis of Prosopis affinis Spreng. (Fabaceae) suggests flexibility of the reproductive system in isolated populations within the Brazilian Pampa. Ann Forest Res 61:37-47. https://doi.org/10.15287/ afr.2018.959

Dressler RL (1981) The orchids: natural history and classification. Harvard University Press, Cambridge

Elle E, Gillespie S, Guindre-Parker S, Parachnowitsch AL (2010) Variation in the timing of autonomous selfing among populations that differ in flower size, time to reproductive maturity, and climate. Amer J Bot 97:1894-1902. https://doi.org/10.3732/ajb.1000223

Freitas L, Sazima M (2009) Floral biology and mechanisms of spontaneous self-pollination in five neotropical species of Gentianaceae. Bot J Linn Soc 160:357-368. https://doi.org/10.111 1/j.1095-8339.2009.00989.x

Goodwillie C, Knight MC (2006) Inbreeding depression and mixed mating in Leptosiphon jepsonii: a comparison of three populations. Ann Bot (Oxford) 98:351-360. https://doi.org/10.1093/aob/ mcl105

Goodwillie C, Kalisz S, Eckert CG (2005) The evolutionary enigma of mixed mating systems in plants: occurrence, theoretical explanations, and empirical evidence. Annual Rev Ecol Evol Syst 36:4749. https://doi.org/10.1146/annurev.ecolsys.36.091704.175539

Groll M (1965) Fruchtansatz, Bestäubung und Merkmalanalyse bei diploiden und polyploiden Sippen von Dactylorchis (Orchis) maculata und Gymnadenia conopsea. Oesterr Bot Z 112:657-700. https ://doi.org/10.1007/bf01380557

Gutowski JM (1990) Pollination of the orchid Dactylorhiza fuchsii by longhorn beetles in primeval forests of Northeastern Poland. Biol Conservation 51:287-297. https://doi.org/10.1016/00063207(90)90114-5

Hagerup O (1952) Bud autogamy in some northern orchids. Phytomorphology 2:51-60

Jersáková J, Johnson SD, Kindlmann P (2006) Mechanisms and evolution of deceptive pollination in orchids. Biol Rev 81:219-235. https://doi.org/10.1017/s1464793105006986

Johnson SD, Edwards TJ (2000) The structure and function of orchid pollinaria. Pl Syst Evol 222:243-269. https://doi.org/10.1007/ bf00984105

Johnston MO, Porcher E, Cheptou PO, Eckert CG, Elle E, Geber MA, Kalisz S, Kelly JK, Moeller DA, Vallejo-Marin M, Winn AA (2009) Correlations among fertility components can maintain mixed mating in plants. Amer Naturalist 173:1-11. https://doi. org/10.1086/593705

Kalisz S, Vogler D, Fails B, Finer M, Shepard E, Herman T, Gonzales R (1999) The mechanism of delayed selfing in Collinsia verna (Scrophulariaceae). Amer J Bot 86:1239-1247. https://doi. org/10.2307/2656771

Kalisz S, Randle A, Chaiffetz D, Faigeles M, Butera A, Beight C (2012) Dichogamy correlates with outcrossing rate and defines the selfing syndrome in the mixed-mating genus Collinsia. Ann Bot (Oxford) 109:571-582. https://doi.org/10.1093/aob/mcr237 
Kamińska E, Miernicka I, Mroz I, Sarosiek J (1990) Ecological organization of the population of Dactylorhiza fuchsii (Druce) Soó. Acta Univ Wratislawiensis 1055:77-93

Kullenberg B (1961) Studies in Ophrys pollination. Zool Bidr Uppsala $34: 1-340$

Liu KW, Liu ZJ, Huang LQ, Li LQ, Chen LJ, Tang GD (2006) Selffertilization strategy in an orchid. Nature 441:945-946. https:// doi.org/10.1038/441945a

Lloyd DG (1979) Some reproductive factors affecting the selection of self-fertilization in plants. Amer Naturalist 113:67-79. https:// doi.org/10.1086/283365

Lloyd DG (1992) Self- and cross-fertilization in plants. II. The selection of self-fertilization. Int J Pl Sci 153:370-380. https://doi. org/10.1086/297041

Lloyd DG, Schoen DJ (1992) Self- and cross-fertilization in plants. I. Functional dimensions. Int J Pl Sci 153:358-369. https://doi. org/10.1086/297040

Love J, Graham SW, Irwin JA, Ashton PA, Bretagnolle F, Abbott RJ (2016) Self-pollination, style length development and seed set in self-compatible Asteraceae: evidence from Senecio vulgaris L. Pl Ecol Diversity 9:371-379. https://doi.org/10.1080/17550 874.2016.1244576

Martens P (1926) L'autogamie chez l'Orchis et quelques autres orchidées. Bull Soc Roy Bot Belgique 59:69-88

Moggridge JT (1865) Observations on some orchids of the South of France. Proc Linn Soc London 9:256-258. https://doi. org/10.1111/j.1095-8312.1865.tb01089.x

Peter CI, Johnson SD (2006) Doing the twist: a test of Darwin's crosspollination hypothesis for pollinarium reconfiguration. Biol Lett 2:65-68. https://doi.org/10.1098/rsbl.2005.0385

Porcher E, Kelly JK, Cheptou P-O, Eckert CG, Johnston MO, Kalisz S (2009) The genetic consequences of fluctuating inbreeding depression and the evolution of plant selfing rates. J Evol Biol 22:708-717. https://doi.org/10.1111/j.1420-9101.2009.01705.x

R Core Team (2017) R: a language and environment for statistical computing. R Foundation for Statistical Computing, Vienna

Reinhard HR (1977) Autogamie bei europäischen Orchideen. Orchidee $28: 178-182$

Suetsugu K (2013) Delayed autonomous self-pollination in two Japanese varieties of Epipactis helleborine (Orchidaceae). Bot J Linn Soc 173:733-743. https://doi.org/10.1111/boj.12111
Suetsugu K (2015) Autonomous self-pollination and insect visitors in partially and fully mycoheterotrophic species of Cymbidium (Orchidaceae). J Pl Res 128:115-125. https://doi.org/10.1007/ s10265-014-0669-4

Szlachetko D, Rutkowski P (2000) Gynostemia Orchidalium I. Acta Bot Fenn 169:1-380

Tałałaj I, Brzosko E (2008) Selfing potential in Epipactis palustris, E. helleborine and E. atrorubens (Orchidaceae). Pl Syst Evol 276:21-29. https://doi.org/10.1007/s00606-008-0082-3

Tałałaj I, Skierczyński M (2015) Mechanism of spontaneous autogamy in the allogamous lepidopteran orchid Gymnadenia conopsea (L.) R. Br. (Orchidaceae). Acta Biol Cracov, Ser Bot 57:1-11. https:// doi.org/10.1515/abcsb-2015-0010

Tremblay R, Ackerman JD, Zimmerman JK, Calvo RN (2005) Variation in sexual reproduction in orchids and its evolutionary consequences: a spasmodic journey to diversification. Biol J Linn Soc 84:1-54. https://doi.org/10.1111/j.1095-8312.2004.00400.x

Vakhrameeva MG, Tatarenko IV, Varlygina TI, Torosyan GK, Zagulskii MN (2008) Orchids of Russia and adjacent Countries (within the borders of the former USSR). A.R.G. Gantner Verlag, Ruggell

Waite S, Hopkins N, Hitchings S (1991) Levels of pollinia export, import and fruit set among plants of Anacamptis pyramidalis, Dactylorhiza fuchsii and Epipactis helleborine. In: Wells TCE, Willems JH (eds) Population ecology of terrestrial orchids. SPB Academic Publishing bv, The Hague, pp 103-110

Yang JQ, Fan YL, Jiang XF, Li QJ, Zhu XF (2018) Correlation between the timing of autonomous selfing and floral traits: a comparative study from three selfing Gentianopsis species (Gentianaceae). Sci Rep 8:3634. https://doi.org/10.1038/s41598-018-21930-9

Zhang ZQ, Li QJ (2008) Autonomous selfing provides reproductive assurance in an alpine ginger Roscoea schneideriana (Zingiberaceae). Ann Bot (Oxford) 102:531-538. https://doi.org/10.1093/ $\mathrm{aob} / \mathrm{mcn} 136$

Publisher's Note Springer Nature remains neutral with regard to jurisdictional claims in published maps and institutional affiliations. 